\title{
La autovía A-381 en el paisaje de las campiñas de Cádiz
}

Ignacio Español Echaniz y David de Santos Marián, Ingenieros de

Caminos, Canales y Puertos

La percepción que las poblaciones tienen del territorio, es decir, su paisaje, tiene que ver con las actividades que desarrollan en él. La manera de moverse sobre el territorio explica el modo que se tiene de entenderlo y apreciarlo.

Ya de antiguo el paisaje de las campiñas de Jerez de la Frontera y de Medina Sidonia ha sido el característico de un territorio de agricultura extensiva organizado mediante una jerarquía de núcleos de población centrales que se completa con el salpicado regular y disperso de poblados y cortijos, centro residencial de las grandes explotaciones agrarias. Esta organización polinuclear y regular de las campiñas resultó eficaz con los sucesivos cambios de orientación de las fronteras y también luego cuando sirvió a una organización ordenada de la explotación de los recursos agrarios.

La tupida red de caminos existentes entre los pueblos, los poblados y los cortijos vendría a explicar muy bien la relación que la población ha tenido con su paisaje a lo largo de su historia. Ya desde la época de los romanos existían calzadas que cruzaban la campiña y la relacionaban tanto con la costa, con Cádiz, como con el interior (Sevilla). La conquista por parte de los cristianos de las comarcas fronterizas al reino nazari de Granada debió consolidar el eje interior frente a los caminos litorales que desde Cádiz permitían llegar a Algeciras.

Luego, la progresiva construcción de un estado peninsular se tradujo en la consolidación de este eje por el oeste de la campiña de Jerez apoyado en los itinerarios de postas y en los caminos de ruedas y de herradura hasta bien entrado el siglo XVIII.

La industrialización transformó el paisaje de la campiña de Jerez introduciendo la viña y las bodegas del ámbito prelitoral de la Bahía de Cádiz y trajo, en 1853, la linea de Jerez al muelle del Trocadero, en Puerto Real, el primer ferrocarril de Andalucia y uno de los primeros de España. El ferrocarril introdujo una mayor capacidad de viaje: grandes volúmenes de personas y productos podian ser transportados con velocidad por el territorio. Con ello trajo también una nueva relación del viajero con el paisaje, ahora más apresurado y más distante aún que antes, también más visual e intelectualizado.

La modernización en el siglo XIX y el primer tercio del siglo XX introdujo primero la red de caminos carreteros y luego las carreteras con firmes manteniendo el itinerario del oeste de la campiña de Jerez, con la N-IV, y el de la costa, con la N-340. Se incrementó así la velocidad y calidad del viaje, también su capacidad. La segunda mitad del siglo XX asistió a una profunda revolución social. La motorización y el desarrollo de la industria en las dos bahías gaditanas hicieron perder peso a la agricultura, fomentando el crecimiento de las ciudades medias en detrimento de la red de asentamientos más rural y disperso.

El aumento de la velocidad que permitieron los nuevos vehículos y carreteras provocó un cierto distanciamiento del medio que se cruzaba. Se empezó a ver el campo como un lugar diferente y especial, un tanto ajeno a la vida cotidiana y por eso dotado de una identidad singular, primero vista como materialización del atraso y, más tarde, atractiva por su calidad ambiental y paisajistica.

Al inicio de los setenta la construcción de la autopista de SeviIla a Cádiz traía un modelo de infraestructura de alta capacidad que anticipaba la manera actual de entender el territorio y de apreciar su paisaje. La autopista con calzadas separadas y capacidad para un elevado nivel de tráfico conectaba el entorno de Sevilla con el entorno de Puerto Real pasando junto a Jerez con un trazado diseñado para una velocidad elevada. Aislada de sus márgenes por un cerramiento continuo sólo se permite su acceso en unos pocos enlaces, de modo que socialmente tiene una naturaleza "aérea" pues sólo sirve a los extremos y en los enlaces y selectivamente debido al peaje. Por el contrario, tiene una notable presencia física por su anchura y por la velocidad a la que sirve, que le obliga a suavizar las formas del terreno natural generando excavaciones y terraplenes.

La relación del viajero con el paisaje en esta vía es claramente cinematográfica, pues se tiene la sensación de desplazarse frente 

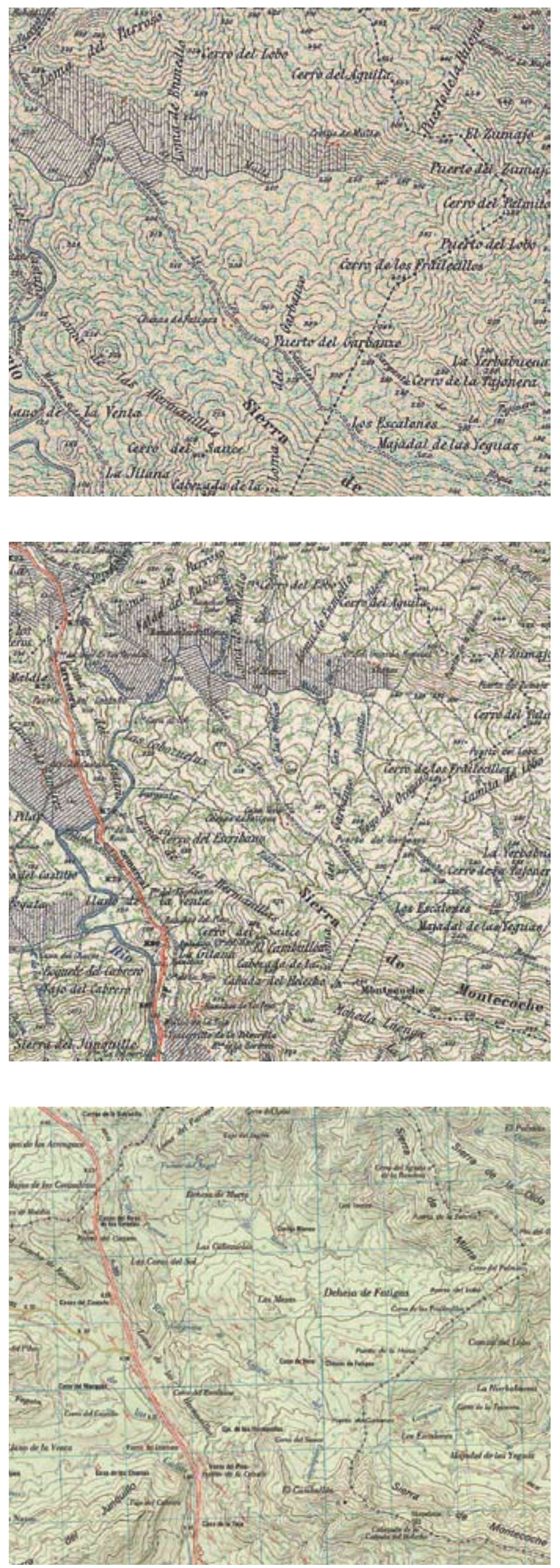

Camino de Alcalá de los Gazules, 1918 (arriba), carretera comarcal, 1960 (centro) y trazado de la Autovía A-381, 2005 (abajo). Los distintos trazados presentan a diferentes lecturas culturales del paisaje. Fuente: Instituto Geográfico Nacional a una serie de imágenes, de paisajes visuales, que se desplazan a sus lados. Además, sus márgenes cierran las vistas a menudo con un denso arbolado de porte dirigiendo la mirada al propio paisaje interior de sus calzadas.

Esta autopista se construyó con un gran esfuerzo tecnológico e innovador para su época, presentándose como un icono de modernidad y progreso que ponía a la región y al pais a la altura de Europa. Asumió así una función simbólica que ya en este milenio se haría común entre las grandes obras públicas al punto de desplazar en importancia social e ideológica a la propia necesidad de su servicio. Su aparición en los años setenta coincide con el inicio del desarrollo de los medios de comunicación visuales que han ganado tanto protagonismo en las actuales actitudes colectivas, colaborando con la simplificación de la idea del paisaje a una mera escena visual.

La autopista de Sevilla-Cádiz sirve a desplazamientos de largo recorrido, en el corredor de la carretera N-IV, desdoblada en autovia finalmente en 1993. La red de carreteras que recorren las campiñas se fue mejorando sirviendo tanto a desplazamientos comarcales como a la centralidad local de sus núcleos urbanos. Éstos, aunque debilitados por la competencia de las grandes ciudades centrales de la costa y Jerez, y por el creciente desarrollo del turismo de playa, han seguido manteniéndose como enclaves de referencia social. La carretera N-340, una actualización del antiguo itinerario litoral y hoy día desdoblada en autovía en casi todo su recorrido, asumió el servicio de conexión intraprovincial que habria de servir a las relaciones entre las áreas más dinámicas de las dos bahías.

El final del siglo XX ha visto la absoluta generalización del vehículo privado que ha pasado a ser un elemento imprescindible de la vida cotidiana también en las campiñas. La distancia media recorrida fue ampliándose gracias a la mejora de la red y de los vehículos, liberando la estructura tradicional de las áreas urbanas. Esto, unido a un modelo liberal de gestión de los usos del suelo, ha dado paso a un modelo urbano expandido que supera el espacio de la ciudad tradicional extendiéndose como una malla por territorios muy extensos. La jornada diaria de un ciudadano medio puede ahora transcurrir en varias localizaciones distantes entre sí en más de 100 kilómetros. Este modo de vida viene sostenido por un territorio que se ha sintetizado a lo reticular y a sus nodos (núcleos urbanos, nuevos centros comerciales), construido sobre las carreteras y que abandona los amplios espacios intersticiales que quedan entre medio. Éstos se perciben como espacios vacios que son vistos en la distancia desde la red, a la velocidad que reclama la apretada organización del tiempo, como postales de paisajes pintorescos.

En este contexto surge la autovía A-381 de Jerez de La Frontera a Los Barrios, un eje dotado de las capacidades de una vía de altas prestaciones, para la conexión entre dos de los grandes conjuntos urbanos de Cádiz. 
Su aparición en la campiña recuerda en muchos aspectos a la de su antecesora la autopista de peaje Sevilla-Cádiz. La nueva autovía sirve a los desplazamientos entre las áreas más dinámicas de la provincia y gracias a sus numerosos enlaces atiende también a los accesos a los núcleos de la campiña de Medina-Sidonia. Esencialmente es una vía para el reciente modelo urbano expandido, que pone en conexión rápida el empleo, los servicios y las residencias de sus extremos y de la campiña. También prolonga la capacidad de las vías de altas prestaciones conectándose con la AP-4 en Jerez y la A-7 en Algeciras. De esta manera todos los espacios de actividad están ahora más cerca entre sí.

Para proporcionar este servicio de gran velocidad y capacidad, la infraestructura arranca al sur de Jerez y se desliza con grandes curvas por las Ilanuras de regadio, evita la Laguna de Medina, discurre entre Paterna y Medina Sidonia, pasa al sur de Alcalá de Los Gazules y recorta las colas del embalse del río Barbate para adentrarse en el terreno más abrupto del Parque Natural de Los Alcornocales. Cruza sobre la cola del embalse del río Palmones y continúa junto a los meandros del río para acceder finalmente a Los Barrios en el área metropolitana de Algeciras. El trazado de la carretera que antes hacia este servicio se ha mantenido en gran parte de su trazado serpenteando con el tronco de la autovia de manera que la presencia del conjunto de vías es notoria en esos tramos.

Como en el caso de la AP-4 Sevilla-Cádiz, la construcción de esta autovía, una costosa iniciativa asumida por la administración autonómica, ha asumido su función icónica con una fuerte carga de innovación y modernidad que se refiere ahora a un nuevo tipo de progreso que combina servicio y funcionalidad con la necesidad de una adecuada integración paisajística. Técnicamente, la obra despliega elementos de integración a su paso por el Parque Natural de Los Alcornocales como pasos de fauna, restitución de vías pecuarias o miradores del paisaje. A través de procedimientos administrativos especificos e interactivos, durante las tres últimas décadas se ha venido exigiendo a los proyectos de carreteras reducir sus efectos negativos sobre los procesos del territorio, especialmente si se tratan de las valiosas y singulares estructuras de la naturaleza que presentan estas sierras de alcornocales y otros bosques mediterráneos. Es así que la iniciativa de construir una vía de alta capacidad a través de un paisaje especialmente sensible se realiza acompañada de ajustes locales y dispositivos de integración.

A diferencia de la AP-4, la autovía Jerez-Los Barrios sirve a desplazamientos cotidianos de carácter provincial, en realidad de la nueva organización territorial de lo urbano, y en ese sentido, materializa muy bien las aspiraciones de la sociedad contemporánea y su relación con el paisaje real.

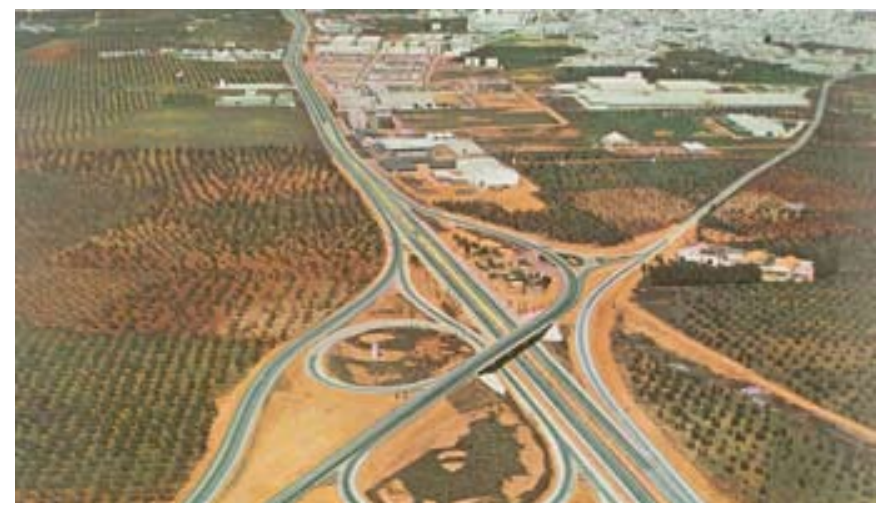

La autopista de Sevilla a Cádiz, un diseño de gran capacidad, hoy superado. Fuente: Bética de Autopistas, S.A. Memoria 1972

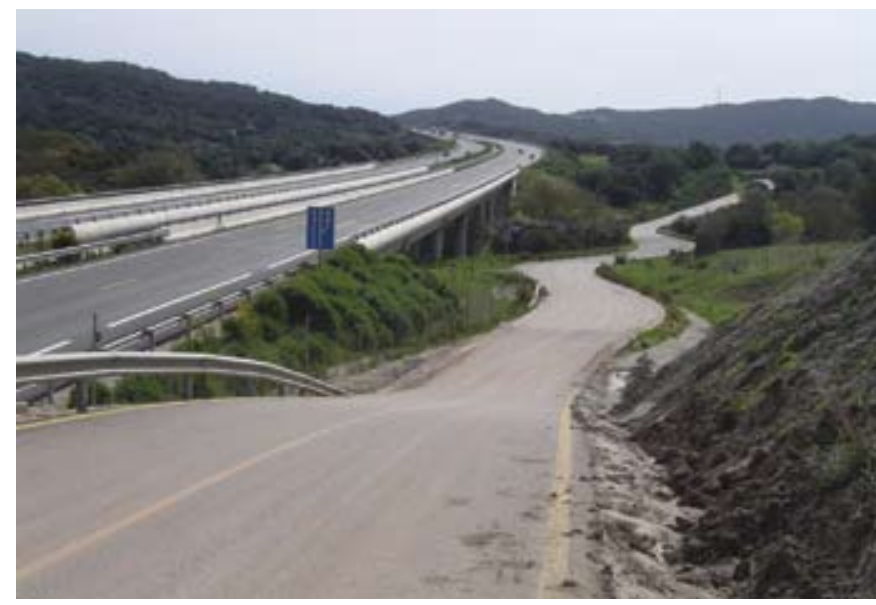

El trazado aéreo de la Autovía A-381 presenta una visión superficial del paisaje. Fuente: Centro de Estudios Paisaje y Territorio (CEPT)

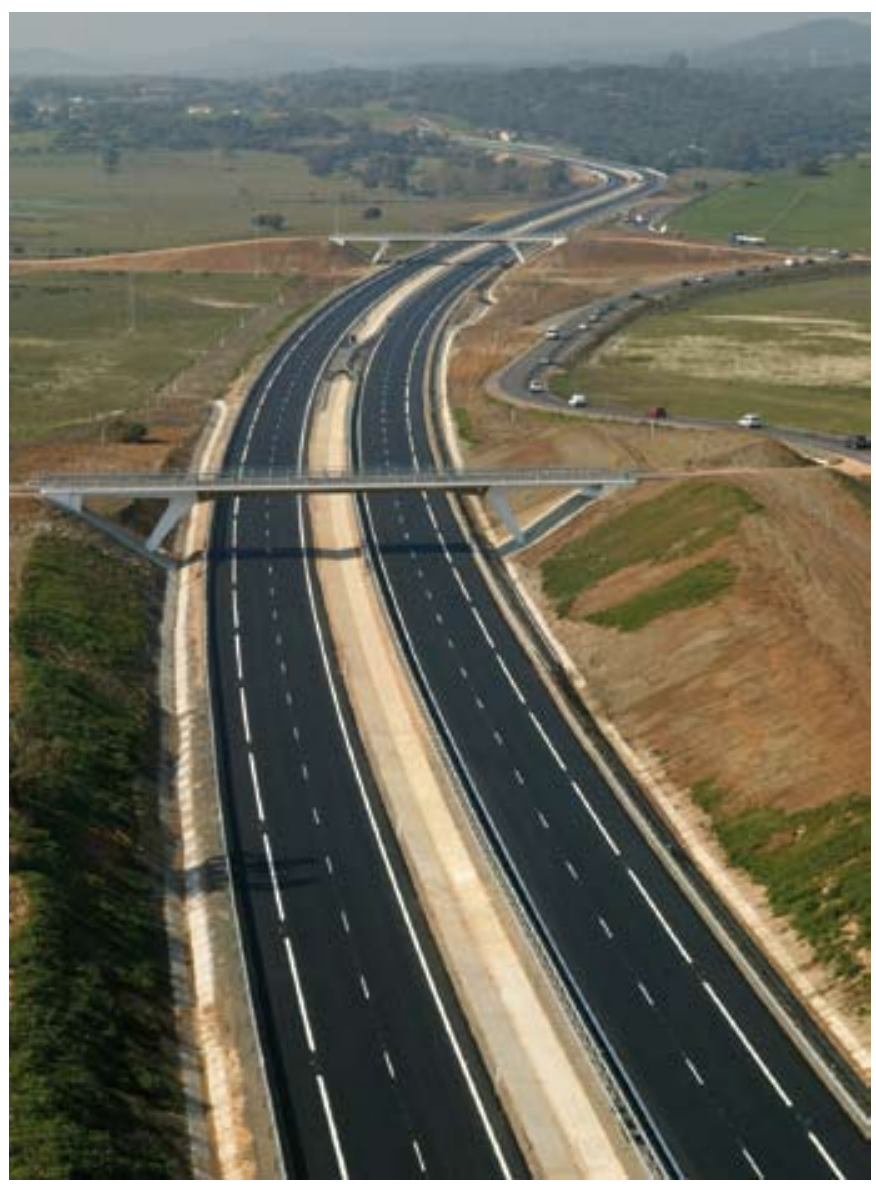

La autovía A-381 entre Jerez y Los Barrios combina servicio y funcionalidad con una adecuada integración paisajística. Fuente: Centro de Estudios Paisaje y Territorio (CEPT) 